\title{
The history of reflex hammers
}

\author{
Douglas J. Lanska, MD
}

\begin{abstract}
Article abstract - Following the simultaneous description of muscle stretch reflexes by Heinrich Erb and Carl Westphal in 1875 , neurologists used direct finger taps or chest percussion hammers to elicit these phenomena. Because of inadequacies of chest percussion hammers for eliciting muscle stretch reflexes, a variety of hammers were developed specifically for this purpose. In 1888, J. Madison Taylor, working for S. Weir Mitchell at the Philadelphia Orthopedic Hospital, designed the first such "reflex hammer." Taylor's hammer had a triangular rubber head and a short, flattened metal handle. Krauss (1894), Berliner (1910), Troemner (1910), Babinski (1912), and Wintle (1925) also designed popular reflex hammers. Many of these hammers and several others are still in use.
\end{abstract}

NEUROLOGY 1989;39:1542-1549

After Erb and Westphal described the clinical usefulness of muscle stretch reflexes in 1875, chest percussion hammers became popular for eliciting these reflexes, coincident with a decline in their use for percussion. Subsequently, neurologists developed hammers specifically for eliciting reflexes; these "reflex hammers" are now critical tools in the neurologic examination.

Percussion hammers. Inspired by the practice of thumping a wine cask to determine the level of fluid, Viennese physician Leopold Auenbrugger (1722-1809) first described the use of percussion as an aid to medical diagnosis in $1761 .^{1-3}$ In his monograph entitled New Invention to Detect Diseases Hidden Deep Within the Chest, Auenbrugger noted that by tapping or percussing with the fingers directly on the chest, back, and abdomen, and listening to the resultant sounds, the condition of the underlying organs could be determined. ${ }^{4}$

In 1826, Pierre Adolphe Piorry (1794-1879), of Paris, described the technique of percussion using a pleximeter $3.5,6$; the pleximeter was a resonator in the form of a small ivory, metal, cedar, or rubber disk that was placed on the chest and struck with a finger. Shortly thereafter ( $c a$ 1828), Scottish physician Sir David Barry (1781-1836) fashioned a small percussion hammer for striking the pleximeter ${ }^{6,7}$ Barry was apparently prompted to develop the hammer by the Swiss veterinary practice of skull percussion for hydatid cysts reported in van Swieten's The Commentaries Upon the Aphorisms of Dr. Herman Boerhaave ${ }^{7}$ :

There have also been ... serous tumours found in the cavity of the cranium, containing a collection of lymph under a thin membrane; and these likewise are capable of producing an apoplexy, when they are increased in their bulk .... Wepfer several times ob- served tumours of the same kind, in brutes; nay he relates, that a vertigo frequently happens to black cattle in the district of Underwold in Switzerland, which the heardsmen cure in the following manner: They strike upon the skull, behind the horns, with a small hammer, and from the sound they discover whether there is any preternatural cavity under the skull; which when they suspect, they immediately bore through the part which they beat upon, and by means of a reed, which they introduce through the hole, they suck out such small bladders as are above mentioned; which if they are situated on the surface of the brain, the cure succeeds; but if they are deeper lodged in the substance of the brain, they have no hopes; wherefore, the butcher who is present, when that is the case immediately kills them. ${ }^{8}$

Unfortunately, Piorry considered Barry's hammer a superfluous invention and it was not widely adopted.6.7

In 1841, German clinician Max A. Wintrich (1812-1882) created the first popular percussion hammer, which was adopted throughout Europe and went through several modifications (figure 1). ${ }^{6.9-11}$ Despite its popularity, Wintrich's hammer was not without critics, including many of those who were advocating their own hammers. Vernon, for example, claimed that there were several "defects of Dr. Winterich's [sic] percussor"12:

It is inconvenient to hold, it is rigid, and it will not produce a note of the same value at each stroke unless the direction in which the axis of the hammerhead strikes the body is the same each time; it requires education to use it, and even then it does not fulfill its purposes.

A wide variety of percussion hammer styles were subsequently developed. Some were T-shaped or L-shaped; others resembled battle-axes, tomahawks, or even magic wands. ${ }^{7,13,14}$ The handles were made variously from

From the Department of Neurology, and the Division of Geriatric Medicine, University Hospitals of Cleveland, and Case Western Reserve University, Cleveland, OH.

Presented in part at the forty-first annual meeting of the American Academy of Neurology, Chicago, IL, April 1989.

Received May 11, 1989. Accepted for publication in final form May 12, 1989.

Address correspondence and reprint requests to Dr. Lanska, Department of Neurology, Albert B. Chandler Medical Center, University of Kentucky, Lexington, KY 40536. 


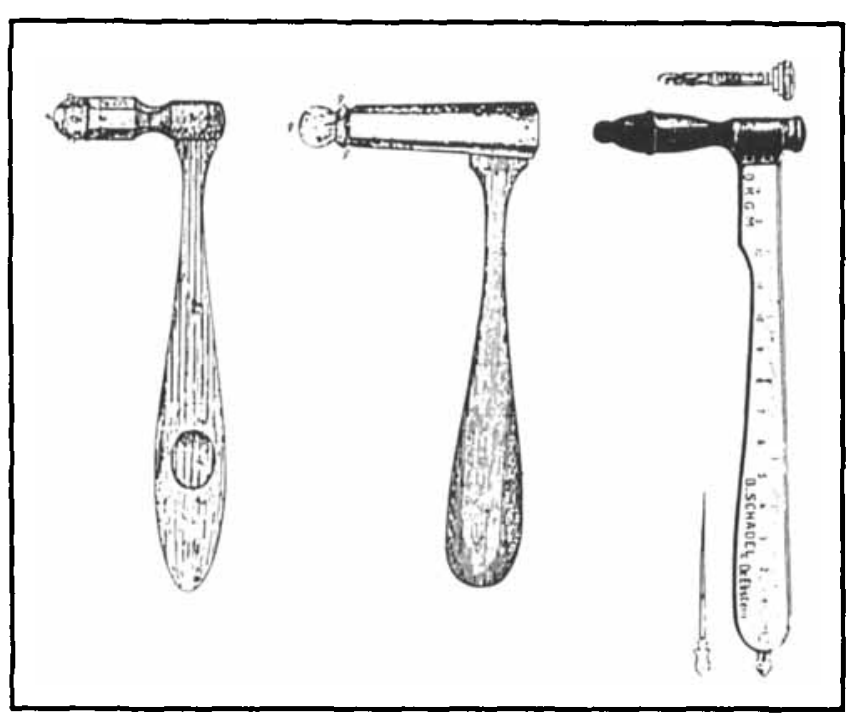

Figure 1. Several versions of the Wintrich hammer, the first popular percussion hammer. (Left) The original version (1841); (center) a later modification by Wintrich (1854); and (right) Ebstein's modification, the "reflex and sensibility tester" (1912). ${ }^{9}$

wood, ebony, whalebone, brass, and other metals, while the heads were of materials such as velvet-covered worsted, wood, rubber, lead, and brass. ${ }^{14}$ In addition to the hammer developed by Wintrich, Flint, ${ }^{15}$ Niemeyer, ${ }^{9}$ Skoda, ${ }^{9}$ Traube, ${ }^{9}$ Seitz, ${ }^{9}$ Vernon, ${ }^{12}$ and others ${ }^{9}$ developed popular percussion hammers. There were so many hammers that Wintrich complained in 1873 , "Presently there are probably as many percussion hammers with so many names attached to them as there are obstetric forceps." 9 (There were over 400 varieties of forceps at the time [J.M. Edmonson, personal communication]).

Muscle stretch reflexes. Almost parallel with the development of percussion, the concept of reflex action was developed in the latter part of the 18th century by Robert Whytt, John Augustus Unzer, and G. Prochaska. ${ }^{16}$ In the 1830 s, Marshall Hall (1790-1857) extended the domain of reflexes to include blinking, swallowing, sneezing, vomiting, and reflexes mediated by the autonomic nervous system. Hall's experimental work, and his formulation of the concept of a "reflex arc," established reflex action as "one of the cornerstones of neurophysiological doctrine."16

Forty years later, in 1875, Erb and Westphal first reported the diagnostic utility of the patellar or kneejerk reflex. Heinrich Erb (1840-1921) was the leading German neurologist of his day, ${ }^{17}$ and the first neurologist to emphasize detailed and systematic examination of the nervous system..$^{18}$ Erb was one of the first to recognize the clinical utility of muscle stretch reflexes, and was the first neurologist to use a percussion ham mer to elicit them, $7,17,19,20$ a practice he initiated around $1870 .{ }^{20}$ After Erb submitted his original paper on the knee jerk ${ }^{19}$ to the German Archives of Psychiatry and Nervous Diseases, he discovered that the editor-Carl Friedrich Otto Westphal (1833-1890) - was preparing a similar paper, and the 2 agreed on simultaneous publication. ${ }^{20}$ In investigating this phenomenon, Westphal

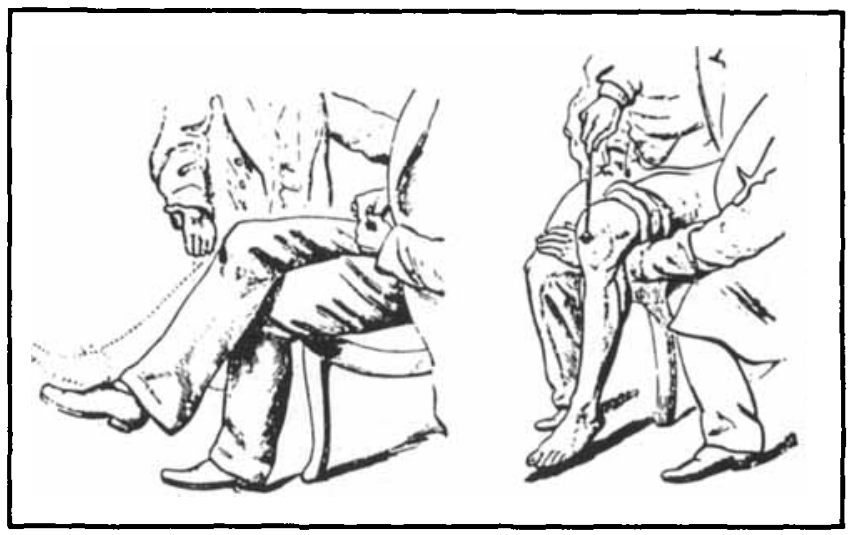

Figure 2. William Gowers recommended eliciting the knee jerk by striking the patellar tendon with the ulnar surface of the hand (left) or a percussion hammer (right). ${ }^{23}$

identified basically the same features as Erb, but while Erb regarded the knee jerk as a simple reflex, Westphal incorrectly thought it resulted from direct excitation of the quadriceps muscle. ${ }^{20.21}$

Early recommendations for eliciting reflexes. In the several decades following Erb's and Westphal's descriptions of the knee jerk, the number of reflexes described proliferated wildly. Not surprisingly, the nomenclature and techniques for eliciting these newly described tendon reflexes varied considerably. In 1875 , Erb had recommended obtaining what he called the "patellar-tendon reflex" by striking the tendon with either a finger or a percussion hammer. ${ }^{19}$ Westphal similarly recommended eliciting the "knee phenomenon" by percussing the patellar ligament "lightly but ... quickly with a finger-best when the index finger is put on top of the middle finger and the former is accelerated downward-or even more effectively with a percussion hammer." 20 In the 1880 s, William Gowers (1845-1915) recommended obtaining the "knee jerk" or "myotatic reflex" by striking the patellar tendon with the ulnar surface of the hand (figure 2).22.23 "Now and then, when very slight, a percussion hammer ... or a stethoscope with an india-rubber edge to the ear piece elicits it more readily."22

In the next several decades, tapping tendons with percussion hammers became the preferred technique. Some neurologists even championed specific models of percussion hammers. Charcot (1825-1893), for example, recommended a Skoda percussion hammer for obtaining the knee jerk. ${ }^{18}$ Joseph Babinski (1857-1932), Charcot's pupil, was also an advocate of hammers: "One should not ... [elicit muscle stretch reflexes] ... with the side of the hand .... One would be better served to use a percussion hammer...."24 In Germany, neurologist Bernhard Berliner was one of the most adamant advocates of hammers, since he felt "it is not very elegant to percuss the knee or achilles tendon with a paper weight, the edge of a large electrode, the foot of a laboratory stand, a table lamp, or similar devices."25

Reflex hammers. Because of inadequacies of percussion hammers for eliciting muscle stretch reflexes, a 
variety of hammers were developed specifically for this purpose. As noted by Berliner, ${ }^{25}$

Not uncommonly, the standard percussion hammers are inadequate for the testing of tendon reflexes, such as in patients with physiologically weak reflexes, in pathologically hyperactive states, and in individuals who, despite all attempts, remain tense. Even if, with sufficient patience and some inconveniencing of the patient, one will almost always obtain a usable result, this goal can be achieved faster and more comfortably by using an instrument which, for one, is heavier than the usual percussion hammer, and secondly, strikes the tendon over a larger surface .... With the small head of the common percussion hammer, the achilles tendon, especially in the supine patient, cannot always be struck securely. Some then resort to turning the hammer around and striking with the handle's edge, a method which again is not elegant, and is unpleasant to the patient.

Troemner's comments were similar ${ }^{26}$ :

Examination of deep tendon reflexes [requires] ... a hammer which is heavy enough to facilitate brief but forceful percussion of the tendon without eliciting pain .... In order to elicit this reliably, the commonly used or recommended small percussion hammers, stethoscopes, house keys, and percussion with the ulnar surface of the hand may be insufficient.

In addition to the greater weight and larger striking surface of these new "reflex hammers," some hammer designers incorporated a handle with a pointed tip to facilitate testing of cutaneous reflexes, ${ }^{25,26}$ a ruler along the handle, ${ }^{9,10,27}$ and a pin, brush, or other tools for testing sensation. $9,10,27$

The first "reflex hammer" was probably the triangular-headed hammer designed by John Madison Taylor in Philadelphia in 1888. ${ }^{28,29}$ Krauss (1894), ${ }^{27}$ Berliner (1910), ${ }^{25}$ Dejerine (ca 1910), ${ }^{9}$ Struempell (ca 1910), ${ }^{9}$ Troemner (1910), ${ }^{26}$ Babinski (1912), ${ }^{24}$ Wintle (1925), ${ }^{7}$ and others ${ }^{9}$ developed popular reflex hammers. Some reflex hammers, such as Ebstein's "reflex and sensibility tester" (1912), ${ }^{9,10}$ and the Queen Square hammer ( $c a 1925),{ }^{7}$ were modifications of previously developed percussion hammers. Ebstein, for example, modified Wintrich's percussion hammer of 1841 by adding a removable brush to the head, and a centimeter ruler and a removable pin to the handle (figure 1 , right): $:, 10$

Being fully aware that such combinations may impair an instrument's functioning, I have introduced into the tip of the shaft of [Wintrich's hammer] a needle with a round ... head, held in place with a screw segment. This allows testing of sensation for "sharp" and "dull," as well as the elicitation of abdominal reflexes and so forth. In addition I have straightened the slightly curved shaft ... to facilitate proper use of the centimeter scale, which ... is engraved on both sides ... . The inserted small hairbrush ... can be used to test light touch during the sensory examination .... [The hammer] can, therefore, be properly called a reflex and sensibility tester. ${ }^{9}$

Since many neurologists found that the lightweight percussion hammers were ineffective or produced in-

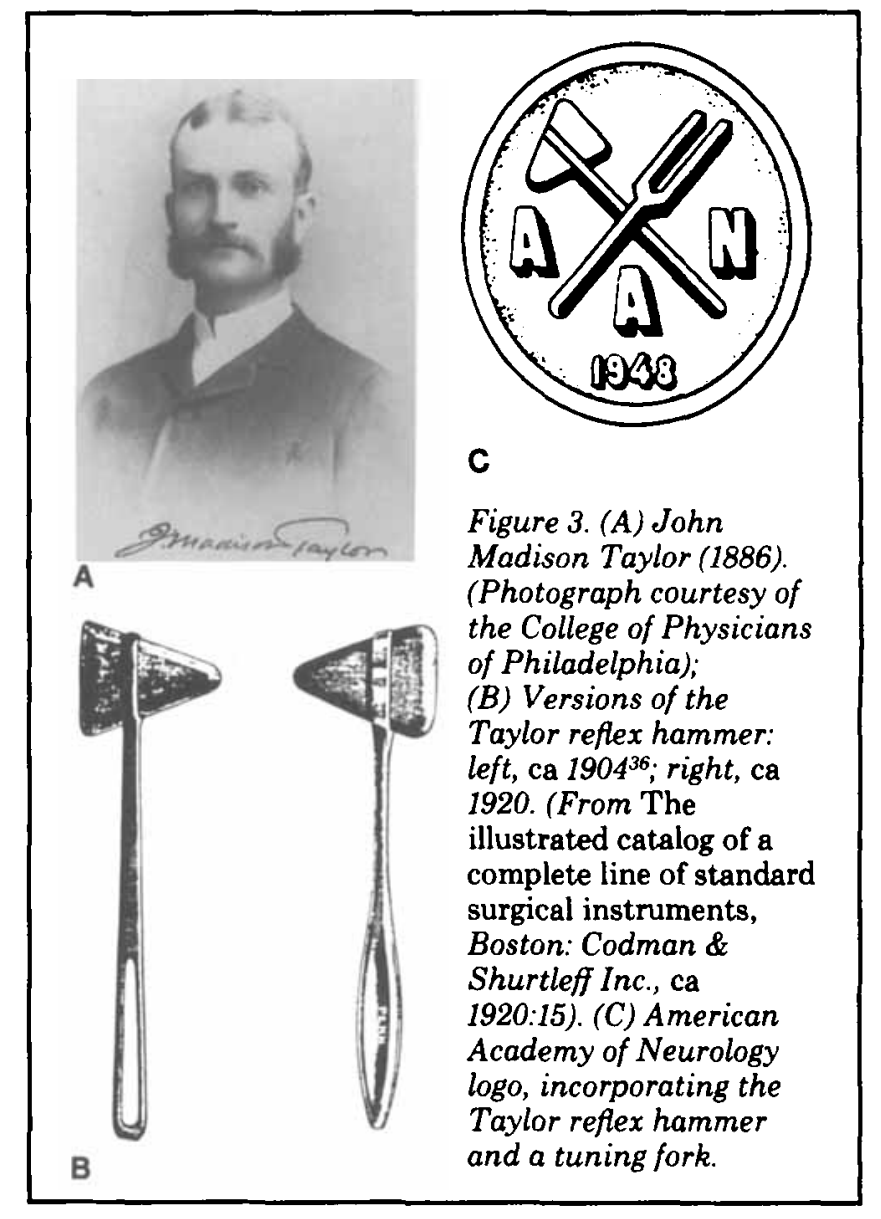

consistent results, ${ }^{25,26,30}$ the most consistent feature of the new reflex hammers was their greater weight. The Taylor hammer (approximately 60 to 70 grams) was considered heavy when it was introduced. ${ }^{31}$ Later hammers were even heavier, weighing between 80 and 140 grams, and some current versions of the Troemner and Queen Square hammers weigh over 200 grams. The added weight of the head, combined in some cases with a longer, flexible handle, increased the hammer's effectiveness, but the applied force was sometimes taken to extremes, as indicated by Berliner's claim that his hammer "allows, in almost all instances, the elicitation of an existing achilles reflex through the patient's boots." 25

Because of the considerable force applied by reflex hammers, Troemner recommended a pleximeter when using a hammer to elicit reflexes: he felt a pleximeter protected "sensitive persons from the striking hammer," and allowed for the elicitation of "percussory muscle reflexes" [eg, deep abdominal reflexes]. ${ }^{32}$ Most neurologists found, however, that the tendons (except the biceps brachii) were best struck directly. With the development of softer rubber striking surfaces and a more refined techique, the need for a pleximeter was eliminated.

The Taylor hammer. John Madison Taylor (1855-1931) (figure 3A) received his medical degree from the University of Pennsylvania in 1878, and then practiced pediatrics, neurology, and physical medicine in 


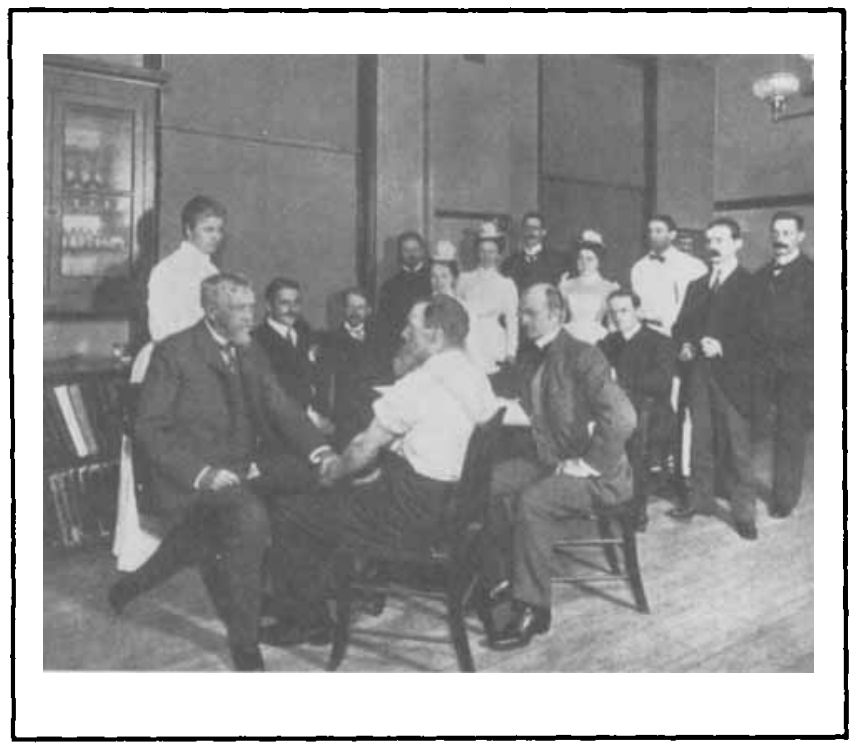

Figure 4. S. Weir Mitchell examining Civil War veterans at the Infirmary for Nervous Disease in Philadelphia (January, 1902). In his right hand, Mitchell is holding a Taylor hammer. J. Madison Taylor is seated to the right of the patient. (Photograph courtesy of National Library of Medicine).

Philadelphia. ${ }^{33}$ From 1882 to 1896 he was the personal assistant of S. Weir Mitchell at the Philadelphia Orthopedic Hospital and Infirmary for Nervous Disease. It was during the early part of his experience at the Orthopedic Hospital that Taylor developed the first true reflex hammer (figure 3B). ${ }^{29}$ The Taylor hammer was praised and popularized by S. Weir Mitchell, ${ }^{28.34}$ and by C.K. Mills, ${ }^{35,36}$ who considered it "the best ham. mer for tapping the much-abused patellar ligament."36

Taylor exhibited his new hammer at the February 27, 1888 meeting of the Philadelphia Neurological Society ${ }^{29}$ with William Osler and Charles K. Mills present in the audience. As noted in the minutes of the meeting:

[Taylor's hammer was] devised to serve as nearly as possible all ends for which a hammer is likely to be called into use by clinicians. This feature at least would, [Taylor] thought, commend it. In shape it is a cone flattened on the opposite side, with apex and base carefully beveled or rounded, of about the thickness throughout of the human index finger. The material is moderately soft rubber. It is held by an encircling band of metal midway between the apex and base transversely, and from it, on the edge, depends the straight handle. The handle is rigid though light, it being Dr. Taylor's opinion that this had better be under the full control of the wielder. If elastic as recommended by some, an element of uncertainty enters in the degree of force used in the blow. The special feature of this hammer is that the shape of the striking surface is like the outer surface of the extended hand, palm downward, which is most often used in obtaining tendon jerk. The rounded apex end is adopted [sic] to reach the biceps tendon at the bend of the arm [and, according to S. Weir Mitchell, "to get muscle responses by a direct blow on the muscle."28] ... . This little tool will also well serve to elicit chest sounds, to percuss the abdomen, and in fact, is useful whenever an elastic hammer is

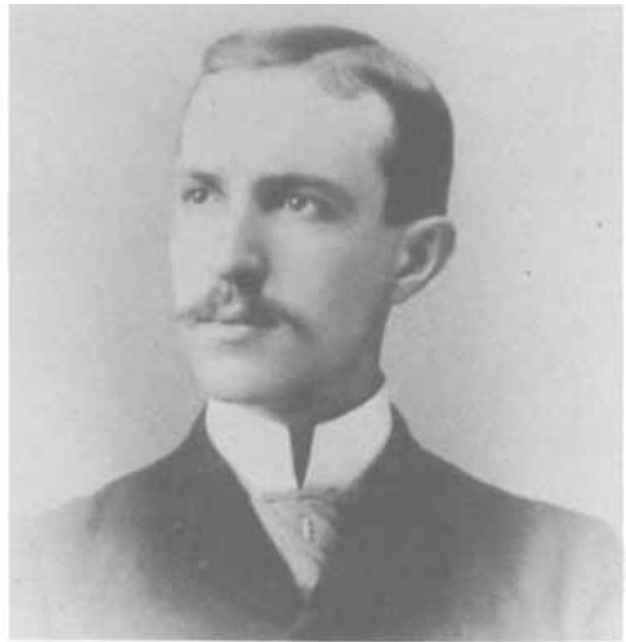

A

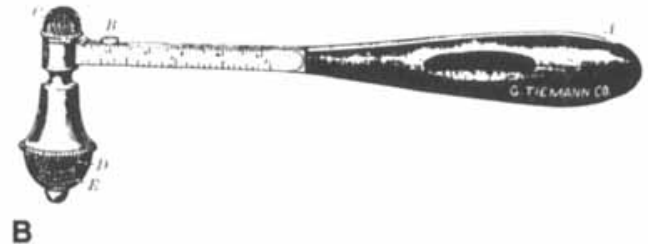

Figure 5. (A) William Christopher Krauss. (B) The Krauss reflex hammer (1904). ${ }^{27}$

needed. The material being of soft rubber, the blow does not hurt the intercepting fingers as does the hammer usually employed to strike the tendons and muscles. It is made by Snowdon [Brothers' Surgical Instruments Co.] of Philadelphia. ${ }^{29}$

The early versions of the hammer had an open loop handle, but some versions after about 1920 had a solid handle with a pointed tip for eliciting cutaneous reflexes (figure 3B). Decades later, the American Academy of Neurology incorporated the Taylor hammer into its logo (figure 3C).

Taylor's interest in muscle stretch reflexes was sparked largely by $\mathrm{S}$. Weir Mitchell's interest in reflexes at the Infirmary for Nervous Disease (figure 4). From 1886 to 1890 , Mitchell published a series of papers related to reflexes, which showed that they could be reinforced with sensory stimuli or, in support of Jendrassik's observation, ${ }^{37}$ with voluntary contraction of other muscle groups. ${ }^{28,38-40} \mathrm{He}$ also introduced the symbols $\mathrm{KJ}+, \mathrm{KJ}++$, and $\mathrm{KJ}-$ for exaggerated, excessively exaggerated, and depressed knee jerks. ${ }^{18}$ In addition, Mitchell's pupils made a number of important contributions: Morris Lewis described the jaw jerk, ${ }^{23,41}$ and Guy Hinsdale and J. Madison Taylor investigated the crossed adductor reflex. ${ }^{42,43}$

The Krauss hammer. William Christopher Krauss (1863-1909) (figure 5A) received his medical degree in 1886 from the Bellevue Hospital Medical College, and after 2 further years of study in Berlin, Germany, he practiced neurology and pathology in Buffalo, New 


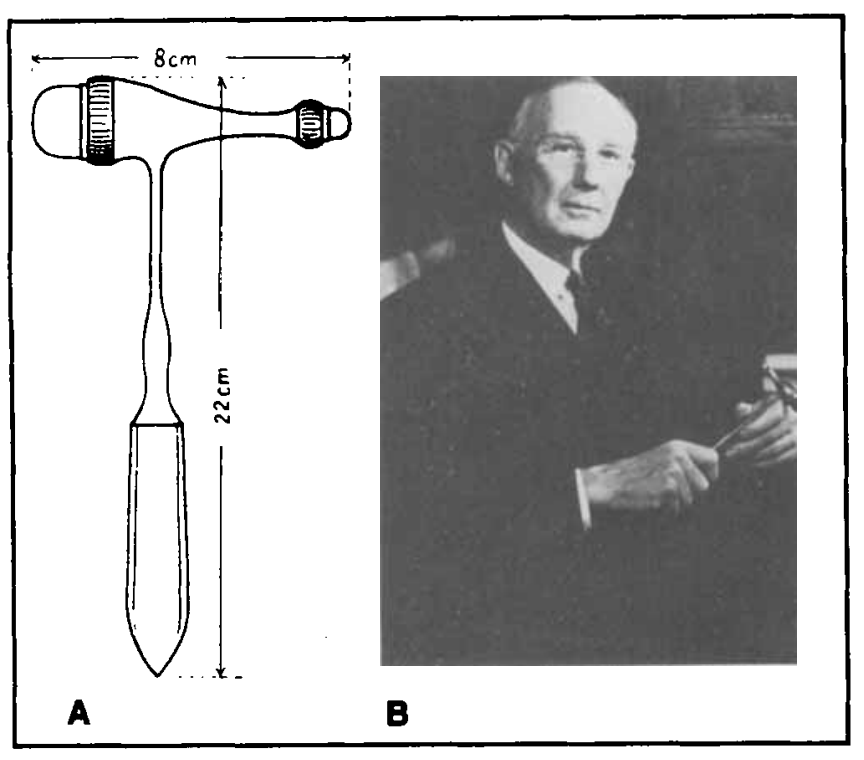

Figure 6. (A) The Troemner reflex hammer (1910). ${ }^{26}$ (B) Henry Woltman holding a Troemner hammer. ${ }^{47}$ (Photograph courtesy of Donald Mulder, MD).

York. ${ }^{44}$ In the course of his career, he designed several new instruments, including "a neuro-topographical bust, an improved tape measure, a new urethral electrode, a pedo-dynamometer, ${ }^{45}$ and a neurological percussion hammer." ${ }_{44}$ The Krauss hammer (figure 5B) was one of the earliest reflex hammers to incorporate modifications for testing sensation as well as reflexes. ${ }^{27}$ Krauss exhibited his hammer at the 20th annual meeting of the American Neurological Association held in Washington, DC in $1894 .{ }^{27}$ It was manufactured by the G. Tiemann Company of New York. ${ }^{27}$ According to Krauss ${ }^{27}$ :

Having had occasion to make constant use of [a percussion] hammer in my private and hospital practice, I have devised some improvements and modifications which widen the field of its usefulness, thus making it more serviceable to those engaged in neurological research. The hammer is constructed after the French pattern having a heavy metallic head fixed to a flattened oval handle seventeen centimetres long. As a hammer it may be used to examine the tendon and muscular reflexes, to percuss the head spine, superficial nerves, etc. The handle (a) [see figure] being of hard rubber becomes warm on friction, while the head being of metal remains cold, thus offering the means of examining the sense of heat and the sense of cold, fulfilling the requirements of [a] thermo-aesthesiometer. The cap (c) when removed discloses a triangular spear head about onehalf centimetre long, while at the other end of the hammer head is the rounded rubber points - the two ends furnishing, therefore, a sharp and a dull point for examining for anaesthesia or hyperaesthesia.... The spear is divisible into two portions, one securely fixed upon the hammer head, the other moveable upon a metallic slide upon which is engraved the metric and English scales. This arrangement furnishes an excellent aesthesiometer and is as accurate and convenient as any on the market. Replacing the cap (c) and removing the cap (e) a camel's hair brush is exposed, giving a soft

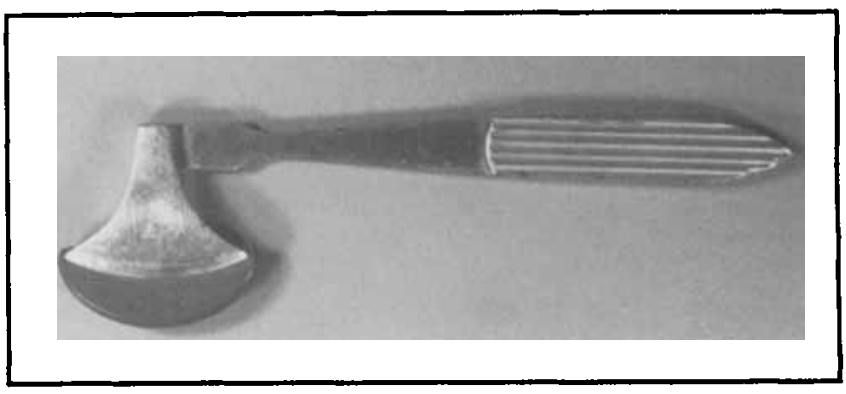

Figure 7. The Berliner reflex hammer (1910). (Photograph courtesy of the Dittrick Museum of Medical History, Cleveland, $\mathrm{OH}$ ).

surface, while the metallic cap (c) gives a hard surface. The hammer is conveniently carried in the pocket, and has served me with much satisfaction.

The Troemner hammer. German neurologist Ernst L.0. Troemner (1868-1930) was director of the Neurological Hospital at St. Georg in Hamburg and professor of the University of Hamburg. In 1910, he developed a reflex hammer (figure $6 \mathrm{~A}$ ), which subsequently became very popular in Germany and in the United States. ${ }^{26,46}$

\section{In describing his hammer, Troemner wrote, ${ }^{26}$}

A frequently-experienced urge stimulated me ... to construct a totally usable hammer, partly based on an older French model. The hammer, which is all metal, weighs approximately $100 \mathrm{grams}$, is 22 centimeters long, lies comfortably in the hand, and has a head of 8 centimeters width, with knobs of rubber at both ends which can be easily exchanged. The large head is designed for use on the large tendons of the extensor surfaces (patellar, achilles, triceps reflexes) and especially for eliciting periosteal and joint reflexes which can be quite painful with the use of smaller hammers, espcially in hyperalgetic patients. The smaller head is used for percussion of flexor tendons (biceps humeri, biceps femoris, and semitendinosus) .... The smooth handle of the hammer can be easily cleaned and in a pinch may be utilized as a tongue blade. Its sharpened edge, in addition, elicits cutaneous and vascular reflexes. The hammer is being fabricated by B.B. Cassel in Frankfurt [and Krauth and Company in Hamburg ${ }^{46,47}$ ], costs 8 marks, and contains 2 substitute rubber heads.... My personal experience in several hundred healthy persons and patients with nervous diseases, newborns as well as elderly, who in part were evaluated with my new hammer, demonstrated much greater constancy of most tendon reflexes throughout all ages than has been previously acknowledged.

Ebstein, ${ }^{9}$ in a paper on percussion hammers, argued against the practice of using the hammer shaft as a tongue blade:

For hygienic reasons, nowadays, a physician would hardly utilize the hammer's shaft as a tongue depressor as Seitz used to do... since the tip of the shaft is customarily used to elicit, for instance, the plantar reflex or Babinski reflex from the sole of the foot.... 


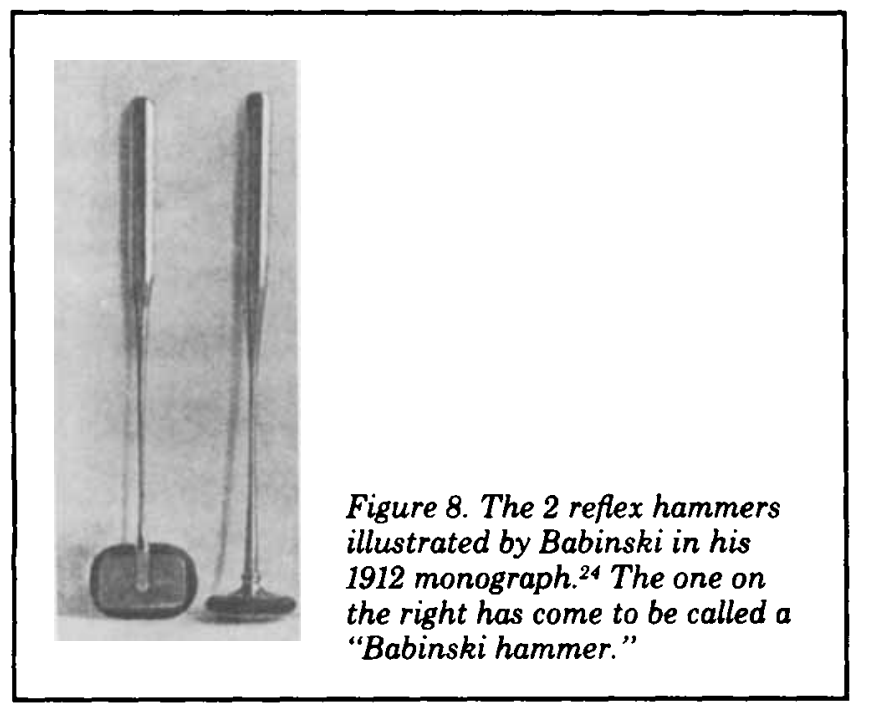

In 1927, Dr. Henry W. Woltman (1889-1964) (figure $6 \mathrm{~B})$, then associate professor of neurology at the Mayo Clinic, spent 6 months in Europe visiting the leading neurological centers (C.W. Nelson, personal communication). ${ }^{46,47}$ In Hamburg, he was greatly impressed by the balance and design of the Troemner hammer. Woltman bought several of the hammers for himself and his colleagues in Rochester, Minnesota. ${ }^{46}$ Subsequently, the Troemner hammer became a tradition among Mayo Clinic neurologists, ${ }^{46}$ and, for many years, gold-plated Troemner hammers were given to emeritus professors and to distinguished visiting neurologists (J.P. Whisnant and D.W. Mulder, personal communications).

The Berliner hammer. The German neurologist Bernhard Berliner described his reflex hammer in 1910 (figure 7). ${ }^{25}$

\begin{abstract}
I constructed a hammer which [has a sufficiently heavy head and a large striking surface], and which in every case proved more useful and comfortable for the testing of tendon reflexes than the common percussion hammers. Such a device has not been available commercially and it appears, therefore, justified to introduce this hammer into our instrumentarium. The device has the shape of a hatchet, and an edge covered with rubber, which always strikes the tendon along its total width .... It is made of metal and nickel-plated. The handle is tapered at the end and may be used for testing skin reflexes .... It is being produced by Louis and $\mathrm{H}$. Lowenstein, Berlin. The shape and larger weight of the new hammer facilitates easy and reliable testing of the achilles tendon reflex in all instances, even in the supine patient ... .
\end{abstract}

The Babinski/Rabiner hammer. French neurologist Joseph François Babinski is best known for the "toe phenomenon," which he described in $1896 . .^{8}$ In 1912 , Babinski wrote a monograph ${ }^{24}$ on reflexes, in which he described 2 reflex hammers (figure 8):

Here I will describe two which are the most frequently used. One of them is composed of a handle of nickel-plated steel which is $20-25 \mathrm{~cm}$. long and fixed at the center with a disk which is made of the same

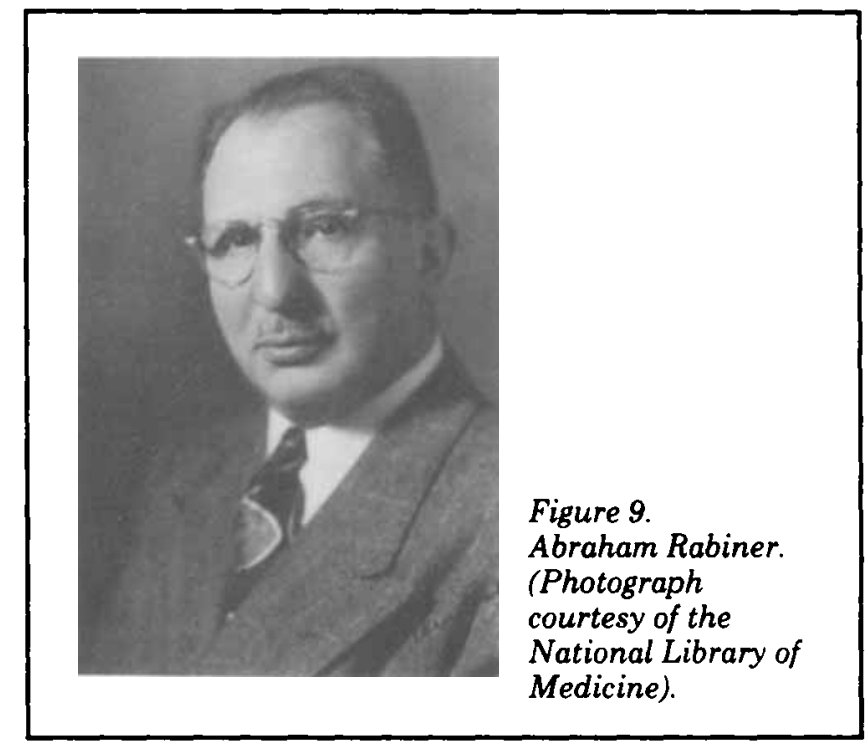

substance and which has at its circumference a furrow filled with a ring of rubber. In the second type, which has an advantage of being able to more easily fit into a pocket, the handle is basically the same as the first type of hammer, but the disk is replaced by a rectangular plaque which is found in the same plane as the handle and is equally provided with a rubber ring in its peripheral canal. These hammers are endowed with elasticity which conforms to the function on which they are called to fulfill.

The former hammer, with the head fixed perpendicular to the shaft, has come to be called a "Babinski hammer" (figure 8, right), although it seems that Babinski's role was more of popularization than invention or development.

Around 1920, Babinski and other neurologic colleagues met in Vienna for a "black tie affair." One of those present was American neurologist Abraham Rabiner (1892-1986) (figure 9). "Following the dinner, during the cigar and brandy stage ... he and Babinski got into a discussion with fellow colleagues on the physiology of the Babinski response" (R.J. Schwartzman, personal communication, based upon conversations with Rabiner). Rabiner noted that Babinski had never proposed a mechanism for the response and offered his own belief, based largely on phylogenetic speculations, that the Babinski sign was due to "removal of the pyramidal influences... [producing] a reversion to a lower scale with a preponderating influence of the extrapyramidal system." 49 Babinski and Rabiner disagreed strongly. "This discussion was very heated and there was some pushing and shoving and other nonprofessional physical activity" (R.J. Schwartzman, personal communication). Following this altercation, Babinski gave Rabiner his own personal reflex hammer "as a token of support" (figure 10A). Rabiner brought the hammer back to New York and had a modified version produced in which the shaft could be screwed into the shank either perpendicular or parallel to the head (figure 10B). Rabiner's version combined the best features of both hammers described in Babinski's 1912 monograph. ${ }^{24}$. 


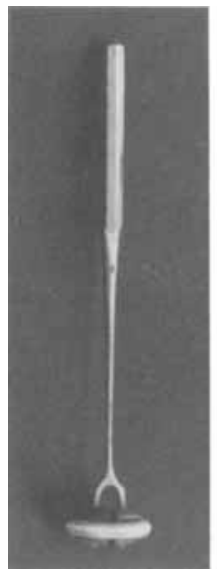

A

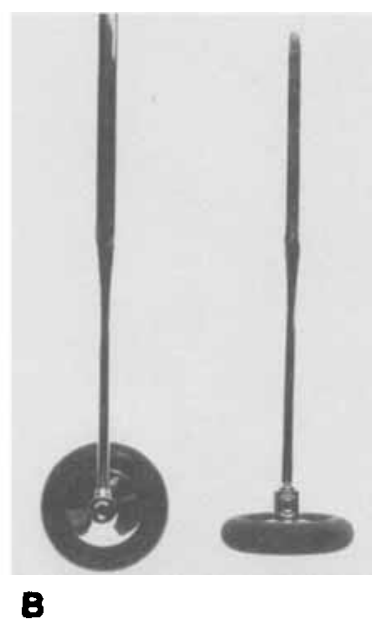

Figure 10. (A) The hammer that Babinski gave to Abraham Rabiner, and that Rabiner later gave to Robert $J$. Schwartzman. (Photograph courtesy of Robert Schwartzman, $M D$ ). (B) The Rabiner reflex hammer. The head can be attached parallel (left) or perpendicular (right) to the shaft.

The Queen Square hammer. The Queen Square hammer was apparently modeled after an earlier chest percussion hammer introduced by Henry Vernon of the Great Northern Hospital in 1858 and manufactured by "Messrs. Whicker and Blaise, of St. Jame's-street" (figure 11). ${ }^{7,12}$ Vernon's hammer

consists of a slender tapering handle of whalebone, eight inches in length, surmounted by a sphere of bell-metal, weighing one ounce. The sphere of metal is grooved deeply in an equatorial direction, and a stout ring of caouchouc [India rubber] is let into the groove, as a cushion upon which to strike. Such is the instrument-simplicity itself. ${ }^{12}$

Macdonald Critchley attributed the Queen Square version of the Vernon hammer to a Miss Wintle, who was the head nurse of physiotherapy and radiology at the National Hospital for Nervous Diseases, Queen Square, London. ${ }^{7}$ Because she was responsible for the electrotherapeutic instruments, she was nicknamed "Sister Electrical." Around 1925, she "hit upon the happy device of fitting a ring pessary to a solid brass wheel, and mounting this upon a stick of bamboo...." (Macdonald Critchley quoted by Schiller). ${ }^{7}$ The bamboo cane was flexible, approximately 8 inches long and $1 / 4$ inch in diameter (R.D. Snyder, personal communication). On one end, a rubber ring was tightly fitted on a

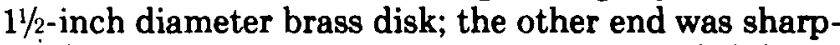
ened to a point for use in eliciting plantar and abdominal responses. "The result was a heavy, springy, and completely painless hammer.... For years she made these herself ... and sold them to post graduate students ... [and] resident medical officers .... (Macdonald Critchley quoted by Schiller). ${ }^{?}$

Conclusion. According to Schiller, in 1875 Erb and Westphal "hit upon the unique spot in the body where scientific purity and simplicity reign because only 2

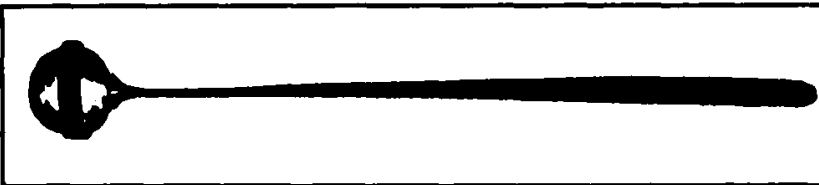

Figure 11. The Vernon percussion hammer $(1858)^{12}$ was the precursor of the Queen Square reflex hammer.

neurons are involved in the [muscle stretch] reflex.... While neither reflexes nor hammers were much newer than pitchforks, they helped in the construction of a new edifice: the functioning nervous system as an assembly of interdependent and hence variably active reflexes...."7 The assessment of reflexes is now an indispensible part of the neurologic examination, and the reflex hammer is a critical tool for that assessment.

\section{Acknowledgments}

The author gratefully acknowledges the assistance and information provided by Arthur K. Asbury, David Y. Cooper, Robert B. Daroff, Noble J. David, James M. Edmonson, Terry Hambrecht, Thomas A. Horrocks, Glenda Jenkins, Mary Jo Lanska, Mark Lloyd, Jan Martin, Mario F. Mendez, Donald W. Mulder, Clark W. Nelson, Polly Rabiner, Bernd Remler, Betty Rabiner Rothfeld, Peritz Scheinberg, Robert J. Schwartzman, Russell D. Snyder, and Jack P. Whisnant.

\section{References}

1. Auenbrugger L. Inventum Novum ex Percussione Tharacis Humani, ut Signo Abstrusos Interni pectoris Morbos Detengendi. Vienna: J.T. Trattner, 1761. Facsimile edition with French, English, and German translations and Neuberger's biography. Vienna and Liepzig: S. Safar, 1922.

2. Rate RG. Leopold Auenbrugger and "The Inventum Novem." J Kansas Med Soc 1966;67:30-33.

3. Bedford DE. Auenbrugger's contribution to cardiology: history of percussion of the heart. Br Heart J 1971;33:817-821.

4. Clendening L. Source book of medical history. New York: Dover, 1942:306-312.

5. Piorry PA. De la percussion médiate et des signes obtenus à l'aide de ce nouveau moyen d'exploration, dans les maladies des organes thoraciques et abdominaux. Paris: Chaude, 1828.

6. Risse GB. Pierre A. Piorry (1794-1879), the French "Master of Percussion." Chest 1971;60:484-488.

7. Schiller F. The reflex hammer. Med Hist 1967;1 1:75-85.

8. Swieten $G$ van. The commentaries upon the aphorisms of Dr. Herman Boerhaave, the late learned professor of physick in the University of Leyden concerning the knowledge and cure of the several diseases incident to human bodies. Volume 10, Section 1010. London: Robert Horsfield and Thomas Longman, 1765:95-96.

9. Ebstein E. Der perkussionshammer. Ein beitrag zur geschichte der mittelbaren perkussion. Arch $f$. Gesch Med 1912;6:245-269.

10. Ebstein E. Perkussionshammer (mit Masstab) und Sensibilitaetspruefer. Muenchener Medizinische Wochenschrift 1912;29:1611-1612.

11. Winterich [sic]. Beschreibung einer neuen Perkussions-Methode. Berliner medizinische Central-zeitung 1841;10:1-4.

12. Vernon $H$. A new percussion hammer. Lancet $1858 ; 1: 141$.

13. Flint A. A practical treatise on the physical exploration of the chest, and the diagnosis of diseases affecting the respiratory organs. Philadelphia: Henry C Lea, 1866:76-79,116.

14. Wilbur CK. Antique medical instruments. West Chester, PA: Schiffer, 1987.

15. Flint A, Emerson H. A manual of auscultation and percussion embracing the physical diagnosis of diseases of the lungs and heart and of thoracic aneurysm and other parts. Philadelphia: Lea \& 
Febiger, 1912:51-53.

16. Hoff HE, Kellaway P. The early history of the reflex. J Hist Med Allied Sci 1952;7:211-249.

17. Viets HR. Heinrich Erb (1840-1921). In: Haymaker W, Schiller F, eds. The founders of neurology, 2nd ed. Springfield, IL: Charles C Thomas, 1970:435-438,

18. McHenry LC. Garrison's history of neurology. Springfield, IL: Charles C Thomas, 1969.

19. Erb WH. Uber Sehnenreflexe bei Gesunden und bei Ruckenmarkskranken. Arch Psychiat Nervenk 1875;5:792-802.

20. Westphal CF. Uber einige durch mechanische Einwirkung auf Sehnen und Muskeln hervogebrachte Bewegungs-Erscheinungen. Arch Psychiat Nervenkr 1875;5:803-834.

21. Tschirjew SI. Urskprung und Bedeutung des Kniephaenomens und verwandter Erscheinungen. Arch Psychiatr Nervenkr $1878 ; 8: 689-712$.

22. Gowers WR. The diagnosis of diseases of the spinal cord, 2nd ed. London: J \& A Churchill 1881:19-34.

23. Gowers WR. A manual of diseases of the nervous system. Philadelphia: P. Blakiston, Son \& Co, 1888:34-41.

24. Babinski J. Réflexes tendineux \& réflexes osseux. Paris: Imprimerie Typographique $R$. Tancrede, 1912.

25. Berliner B. Ein neuer Hammer zum Pruefen der Sehnenreflexe. Dtsch Med Wochenschr 1910;33:1532.

26. Troemner E. Ein neuer Reflexhammer; zugleigh ein Beitrag zur Pruefung von Sehenreflexen. Berl Klin Wochenschrift 1910;21:997-998.

27. Krauss WC. A neurologist's percussion hammer. J Nerv Ment Dis 1894;21:686-688.

28. Mitchell SW. On the muscular reactions known as tendon-jerks and muscle-jerks. Med News 1888;52:677-685.

29. Taylor JM. New form of percussion hammer. J Nerv Ment Dis 1888;15:253.

30. Troemner E. Ueber Sehen-resp. Muskelreflexe und die Merkmale ihrer Schwaechung und Steigerung. Berl Klin Wochenschrift 1913;50:1712-1715.

31. Truax C. The mechanics of surgery. Chicago: C. Truax \& Co., 1899.

32. Troemner E. Zur Technik der Reflexpruefung. Klin Wochenschr 1923;2:1810-1812.

33. Solis-Cohen S. John Madison Taylor: an appreciation. Trans Coll Surg (Philadelphia) 1932;54:76-82. [See also Med J and Record
1932;136:39-40].

34. Mitchell SW, Dercum FX. General considerations. In: Dercum FX, ed. A textbook on nervous diseases by American authors. Philadelphia: Lea Brothers, 1895:29.

35. Mills CK. The nervous system and its diseases. Philadelphia: J.B. Lippincott, 1898:173.

36. Mills CK. Neurology in Philadelphia from 1874 to 1904. J Nerv Ment Dis 1904;31:353-367.

37. Jendrassik E. Zur Untersuchungsmethode des Kniephaenomens. Neurol Centroblat 1885:4:412.

38. Mitchell SW, Lewis MJ. The tendon-jerk and muscle-jerk in disease, and especially in posterior sclerosis. Am J Med Sci 1886;92:363-372.

39. Mitchell SW, Lewis MJ. Physiological studies of the knee-jerk, and of the reactions of muscles under mechanical and other excitants. Med News 1886;48:169-173,198-203.

40. Mitchell SW. The path of motor and sensory reinforcement. Med News 1890;56:297-299.

41. Lewis MJ. The chin reflex: a new clinical observation. Polyclinic (Phil) 1884-5;ii:190.

42. Hinsdale G, Taylor JM. Crossed knee-jerk. J Nerv Ment Dis 1894;19:690-692. [See also Trans Am Neurol Assoc $1894 ; 20: 135-137]$.

43. Hinsdale G, Taylor JM. Crossed knee-jerk, or contra-lateral adductor reflex. Intl Med Mag 1896;4:369-376.

44. Watson IA. Physicians and surgeons of America: a collection of biographical sketches of the regular medical profession. Concord, NH: Republican Press Association, 1896:375-376.

45. Krauss WC. An instrument for measuring the strength of the limbs-pedo-dynamometer. J Nerv Ment Dis 1893;20:689-691.

46. Rooke ED. The Troemner hammer: a historical postscript. Rochester, Minnesota: Mayo Clinic, undated.

47. Mulder DW. Henry William Woltman: 1889-1964. In: DennyBrown D, Rose AS, SahB AL, eds. Centennial anniversary volume of the American Neurological Association: 1875-1975. New York: Springer, 1975:259-263.

48. Babinski J. Sur le réflexe cutane plantaine dans certaines affections organiques du système nerveux central. C R Soc Biol (Paris) 1896;48:207-208.

49. Rabiner AM, Keschner M. Theory of the mechanism for the Babinski toe phenomenon. Arch Neurol Psychiat 1926;16:313-318. 


\title{
Neurology
}

\author{
The history of reflex hammers \\ Douglas J. Lanska \\ Neurology 1989;39;1542 \\ DOI 10.1212/WNL.39.11.1542
}

\section{This information is current as of November 1,1989}

\section{Updated Information \& \\ Services}

Citations

Permissions \& Licensing

Reprints including high resolution figures, can be found at:

http://n.neurology.org/content/39/11/1542.full

This article has been cited by 2 HighWire-hosted articles: http://n.neurology.org/content/39/11/1542.full\#\#otherarticles

Information about reproducing this article in parts (figures,tables) or in its entirety can be found online at:

http://www.neurology.org/about/about_the_journal\#permissions

Information about ordering reprints can be found online:

http://n.neurology.org/subscribers/advertise

Neurology $®$ is the official journal of the American Academy of Neurology. Published continuously since 1951, it is now a weekly with 48 issues per year. Copyright (C) 1989 by the American Academy of Neurology. All rights reserved. Print ISSN: 0028-3878. Online ISSN: 1526-632X.

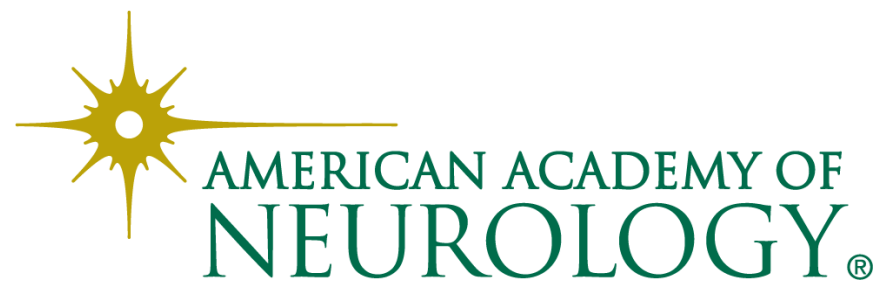

